\title{
Protease Inhibitor Use in COVID-19
}

\author{
Yueqi Song ${ }^{1} \cdot$ Wujian Peng ${ }^{2} \cdot$ Donge Tang $^{1} \cdot$ Yong Dai $^{1}$ (I)
}

Accepted: 6 August 2020 / Published online: 14 August 2020

(C) Springer Nature Switzerland AG 2020

\begin{abstract}
The outbreak of a large plaque, novel coronavirus pneumonia (NCP), which also named Coronavirus Disease 2019 (COVID-19) by the WHO, has detrimentally affected the livelihood and health of people in China. During the spread of COVID-19, colleagues who have been working at the frontline have had to face many new challenges in the treatment and prevention of NCP. Therefore, we have provided suggestions for the diagnosis, treatment, and prevention of the novel coronavirus pneumonia in the current epidemic situation based on the latest reports and the experience of doctors treating COVID-19 in our hospital. We recommend lopinavir/ritonavir as the effective drugs for antiviral treatment according to our experience in administering lopinavir/ritonavir to COVID-19 patients and the successful cases of these drugs in treating MERS and SARS, but need more clinical data to prove their efficacy in treating COVID-19.
\end{abstract}

Keywords Novel coronavirus pneumonia $\cdot$ Diagnosis $\cdot$ Treatment $\cdot$ Lopinavir/ritonavir

\section{Backgrounds}

An ongoing outbreak of a novel disease linked to a novel coronavirus, named severe acute respiratory syndrome coronavirus 2 (SARS-CoV-2), was first reported in Wuhan, China, at the end of 2019 [1]. From that time point on, COVID-19 has been spreading across almost every country. According to statistics from the National Health Commission, more than 200,000 cases were confirmed cases and 8000 deaths from NCP have been reported throughout the world until March 18, 2020, due to the high contagiousness of NCP [2]. In general, the clinical manifestations of NCP patients include fever, cough, shortness of breath, diarrhea, and vomiting [3].

This article is part of the Topical Collection on COVID-19

Yong Dai

daiyong22@aliyun.com

1 Clinical Medical Research Center, The Second Clinical Medical College of Jinan University (Shenzhen People's Hospital), 1017 North Road, Dongmen, Shenzhen 518020, Guangdong, People's Republic of China

2 Department of Nephrology, National Clinical Research Center for Infectious Diseases, The Second Affiliated Hospital of Southern University of Science and Technology (Shenzhen Third People's Hospital), Shenzhen 518114, Guangdong, People's Republic of China
Many organizations including medical health service and scientific research center have taken part in the investigation of SARS-CoV-2 to ensure overall recognition of the novel coronavirus and have shared biomedical research results with other scientists $[4,5]$. On February 12, 2020, World Health Organization (WHO) designated the new type of pneumonia as COVID-2019 [6], and characterized COVID-19 as a pandemic on 11 March 2020 later [7]. Increasing numbers of colleagues at different hospitals and scientific research institutions have devoted their efforts to this outbreak. Thus, we are very eager to instruct medical workers in other areas on how to diagnose and treat NCP patients under the difficult conditions resulting from the novel coronavirus pneumonia, and our advice is based on the latest reports and the experience of doctors treating COVID-19 in our hospital, with the goal of limiting the impact of the epidemic on every medical worker at the frontline as soon as possible.

\section{Pathology}

SARS-CoV-2 is a type of $\beta$-coronavirus, and the enveloped virus pellet usually presents as pleomorphic, and sometimes round or elliptical, with a diameter ranging from 60 to $140 \mathrm{~nm}$. SARS-CoV-2 differs from SARSr-CoV and MERSr-CoV apparently in gene sequence [2]. However, SARS-CoV-2 shares more than $85 \%$ sequence identity with the SARS-like 
coronavirus, which was found in bats based on the whole genome analysis of viruses $[8,9]$.

During the isolation, culturing and identification of SARSCoV-2 in vitro, the virus could be identified in human airway epithelial cells after approximately $96 \mathrm{~h}$, and in Vero E6 cells and Huh-7 cells after approximately 6 days $[10,11]$. The investigation of the physicochemical properties of SARS-CoV-2 has been almost entirely based on research conducted on SARS$\mathrm{CoV}$ and MERSr-CoV in the past. These viruses are sensitive to ultraviolet rays and heat and can be inactivated by exposure to a $56{ }^{\circ} \mathrm{C}$ environment for $30 \mathrm{~min}$, or lipid solvents such as $75 \%$ ethanol, chlorine-containing disinfectant, peracetic acid, or chloroform (except for chlorhexidine) [12, 13].

\section{Epidemiology}

At present, novel coronavirus pneumonia patients are the main source of infection, while asymptomatic carriers may also sometimes be a source of infection [14], but we still cannot determine the origin of infection from wild animals. Respiratory droplets, direct contact, and aerosol are the major channels of transmission, while the involvement of aerosol transmission, gastrointestinal transmission, blood transmission, and mother-child transmission is still unclear [15]. Most populations worldwide, and in China, are generally very susceptible to SARS-CoV-2, and the elderly and patients with other chronic diseases are often in serious condition once infected; however, pet dogs, children, and infants can also develop NCP [2].

\section{Symptom}

The incubation period of SARS-CoV-2 is approximately half of 1-14 days, with most patients showing an incubation period of 3-7 days. Fever, fatigue, and hoose are the main manifestations; and a few NCP invalids have accompanying a stuffy or runny nose, sore throat, diarrhea; and others do not have an obvious fever or other symptoms during the whole course. Most of the severely affected patients exhibit a worsening of symptoms on the 5th to the 8th day of the course of disease, which manifests as a persistent fever, shortness of breath, decrease in blood oxygen saturation, and progression of lung inflammation on chest film or lung CT. The more severely affected cases may deteriorate rapidly and develop acute respiratory distress syndrome, acute renal injury, fulminant myocarditis, septic shock, metabolic acidosis, and coagulation dysfunction, which are difficult to correct [3]. It is emphasized that the course of progression of the severe and critically severe patients can be characterized by a mild or light fever, or even healthy temperature; however, chest imaging (CT) of these patients suggests that the number and extent of lesions significantly increased. We believe this is an important warning for treating such patients [16].

The prognosis of most patients is good, and the symptoms in children are relatively mild. Only a small proportion of patients will be in critical condition, especially some mildly affected patients who develop severe development or who may deteriorate from severe to critical condition [14]. The elderly and patients with diabetes, hypertension, heart disease, and lung disease and other chronic diseases, as well as coinfected people, are high-risk groups [2, 17]. According to examination results from labs, in the early state of COVID-19 infection, leukocytes in peripheral blood maintained or decreased, and lymphocytes were decreased, sometimes showing increases in lactate dehydrogenase, muscle enzyme, myoglobin, and other enzyme in the liver and muscle [18]. In most patients, C-reactive protein (CRP), interleukin-6, and ESR increased and procalcitonin maintained a healthy level. Partially severe/critical patients presented a progressive decrease in peripheral blood lymphocytes, especially $\mathrm{CD}^{+} \mathrm{T}$ lymphocytes, and the amount of serum albumin decreased while troponin and D-dimer levels increased [10, 18]. In contrast, the plasma ACE-2 level was significantly increased. The signaling of nucleic acid of SARS-CoV-2 could be captured in nasopharyngeal swabs, throat swabs, phlegm, lower respiratory tract secretions, feces, anal swabs and blood samples by RT-PCR. The genetic material of SARS-CoV-2 could be also detected in the lung tissue of a critical patient whose alveolar lavage fluid (BALF) was previously detected as negative many times [19]. The detection rates for different types of samples decreased in the following order: lower respiratory secretions $>$ sputum $>$ nasopharynx swab $>$ pharynx swab $>$ feces/anal swab [5]. For patients with typical viral infection symptoms with a two negative nucleic acid tests from nasopharynx swabs or pharynx swabs, it is suggested to test lower respiratory tract secretions for SARS-CoV-2 nucleic acid; it is also possible to detect SARS-CoV-2 IgM and IgG antibodies in serum $[3,19,20]$. In the early stage of COVID-19 infection, there might be several mini patch shadows and interstitial lesion, particularly in the extrapulmonary domain, that might finally develop several ground glass shadows and infiltrative shadows in bilateral pulmonary. Consolidation of lung and hydrothorax emerged in severe cases possibly, but situation of pleural effusion was less than common. It should be emphasized that chest $\mathrm{CT}$ depicts the lung lesions better $[21,22]$.

\section{Diagnostic Criteria}

First, the diagnostic standards of NCP should be used to grade cases as suspected cases and confirmed cases.

Then, a comprehensive analysis of the epidemiological history and clinical symptoms can be used to diagnose the suspected cases; any patient with a relevant epidemiological 
history or any two clinical manifestations was recognized as a suspected case [3, 23].

\section{Epidemiological History}

A. There was a travel history or dwelling history in epidemic areas, with continuous transmission of local NCP cases, within 14 days before the abnormal symptom arose [24].

B. There was contact with an individual with fever or expiratory dyspnea from epidemic areas with continuous transmission of local NCP cases within 14 days before abnormal symptoms arose.

C. There was contact with a confirmed NCP patient with novel coronavirus infection within 14 days before the onset of the disease [25].

D. The patient is part of a cluster associated with the onset of unknown disease with an epidemiological correlation with novel coronavirus infection.

\section{Clinical Symptoms}

A. Fever.

B. The abovementioned image shows the characteristics of pneumonia [26].

C. In the early phase of the disease, leukocytes maintained or decreased in number, and only the lymphocyte decreased [10].

Any suspected case that satisfied any piece of the following epidemiological or clinical criteria was identified as a confirmed case.

A. Novel coronavirus nucleic acid was detected by RT-PCR in respiratory specimens or blood samples.

B. The viral genome sequence obtained from the respiratory tract or peripheral blood samples was almost identical with that of known overt novel coronavirus [27]. Moreover, the antibody titer of the pathogen in the serum of patients in recovery was four times higher than that determined at the onset of disease, which can aid in identifying the pathogen [28]..

\section{Clinical Classification}

COVID-19 patients should be divided into 4 groups based on the severity or progression of the disease: mild type, common type, severe type, and critical type; this will help doctors formulate a targeted treatment strategy.

\section{Mild Type}

Clinical symptoms are moderate; no pneumonia phenomenon is found on CT imaging.

\section{Common Type}

The presence of fever, infection in the respiratory tract and other symptoms, and significant viral pneumonia can be seen on CT imaging [22].

\section{Severe Type: The Presence of Any One of the Following}
A. Respiratory distress: $\mathrm{RR} \geq 30$ times/min.
B. The oxygen saturation at rest is $\leq 93 \%$.
C. Arterial partial pressure of oxygen $(\mathrm{PaO} 2) /$ fraction of inspi- ration $(\mathrm{FiO} 2) \leq 300 \mathrm{mmHg}(1 \mathrm{mmHg}=0.133 \mathrm{kPa})$ [29].

\section{Critical Type: The Presence of Any One of the Following Symptoms}

A. Respiratory failure, requiring the use of the artificial airways to introduce invasive mechanical ventilation $[21,25]$.

B. Shock.

C. Functional failure in other organs, which should be monitored and treated in the ICU $[17,29]$.

\section{Differential Diagnosis}

SARS-CoV-2 is mainly differentiated from influenza virus [30], parainfluenza virus, adenovirus, respiratory syncytial virus, rhinovirus, human metapneumovirus, SARS coronavirus, and other known cause of viral pneumonia [31, 32], and COVID-19 should be distinguished from infectious pneumonia caused by Mycoplasma, Chlamydia, or bacteria as well as non-communicable diseases, including angiitis, dermatomyositis, and organic pneumonia [33].

\section{Treatment}

First, the confirmed cases should be evaluated for the severity of disease, and then, patients should be administered oxygen therapy, antiviral treatment, antimicrobial treatment, immunotherapy, and other treatments according to the specific condition to ensure optimal efficacy [34]. 


\section{Determine the Treatment Site Based on the Severity of the Patient's Condition}

A. The suspected patients should be monitored alone in a single room, and multiple confirmed patients can be treated in group.

B. Critically severe patients should be sent to the infectious ICU as early as possible to receive emergency treatment [17].

\section{Treatment for Mild/Common Type Cases}

\section{Principle}

Try to convalesce in bed, strengthen supportive treatment, and ensure sufficient heat; meanwhile, take care of the balance between water and electrolyte; retain environment stability in vivo; and frequently check the vital signs, oxygen saturation, and so on [15].

\section{Monitoring}

Monitor the blood routine, urine routine, CRP, biochemical indicators (hepatic enzyme, cardiac enzyme, kidney function, etc.), T lymphocyte subgroups, and coagulation function according to the state of an illness; analyze the arterial blood gas; recheck chest imaging if it is necessary; $[16,19]$ and detect SARS-CoV-2 nucleic acid at least once every 3 days $[5,17]$.

\section{Advocate Early Oxygen Therapy}

Oxygen saturation (SpO2) $\geq 93 \%$ without conventional oxygen inhalation, adopt early oxygen therapy through nasal catheters or masks soon after appearing continuous fever, expanding lung lesions, or a trend towards severe development [33].

\section{Antiviral Treatment}

Because there is no specific antiviral treatment method address to NCP, we tried the following schemes.

Scheme A. Aerosol inhalation of interferon-alpha $(5,000,000 \mathrm{U}$ for adults at every turn, $2 \mathrm{ml}$ of sterilized water for injection, two times daily) + lopinavir/ritonavir (200 mg/50 mg/capsule, two capsules at every turn, two times daily) $[35,36]$.

Scheme B. Interferon- $\alpha$ in aerosol inhalation + favipiravir (1600 mgq for $12 \mathrm{~h}$ in the first dose, maintained $600 \mathrm{mgq}$ for $12 \mathrm{~h}$ from the second day) [37].

Scheme C. Took $0.5 \mathrm{~g}$ chloroquine orally twice a day [38]. Scheme D. Added ribavirin $(0.5 \mathrm{~g}$ for adults, intravenously infused twice a day) or $0.2 \mathrm{~g}$ oral abidol tablets three times a day if disease were rapidly devastating and viral nucleic acid continues to be positive based on above schemes [25].

\section{Treatment for Severe/Critical Type Cases}

\section{Principle}

Actively prevent and treat the complications and previous basic disease, completely eradicate the secondary infection, and timely support organ function [29] based on antiviral and symptomatic treatment [17].

\section{Antiviral Treatment}

The treatment plan is the same as mentioned above and additionally suggests that we should pay close attention to adverse the drug effects. Chloroquine is not recommended for critical patients, though suspension of the drug can take the place of lopinavir/ritonavir which was orally taken [39]. Detect SARSCoV-2 nucleic acid once a day and adjust the antiviral treatment plan according to the monitoring results [5]. The plasma in the recovery period and specific antibody are as well considered the optimal choice in the future [32].

\section{Antimicrobial Therapy}

Reinforce the monitoring of bacteria, fungi, and other pathogens inside, and conduct second-generation sequencing if necessary. Use antibiotics according to the test results and patients' condition.

\section{Immunotherapy Measures}

Glucocorticoid can be used soon after the onset of NCP (particularly the 5th-8th day of the course) and the short term (35 th day) according to the clinical symptoms and the concrete situation of CT imaging. The dosage of methylprednisolone is not recommended to exceed $1-2 \mathrm{mg} / \mathrm{kg} /$ day. Vital signs, finger pulse oxygen, blood gas analysis, and chest imaging should also be monitored [17, 40].

Human immunoglobulin is recommended to utilize depending on the patients' clinical symptoms and the progress of chest imaging, and IgM can be used if possible during the progress of the disease [19, 41].

Thymalfasin was given $1.6 \mathrm{mg}$ in subcutaneous injection for 1-2 times a day when peripheral blood lymphocytes or $\mathrm{CD}^{+}{ }^{+}$cells decreased significantly in patients $[10,42]$, and take the intravenous administration of Xuebijing $(100 \mathrm{ml} /$ day, at twice) or Ulinastatin into consideration [43]. Xuebijing, a kind of injection, is widely used in China. At present, Xuebijing produced by the Tianjin Chase Sun 
Pharmaceutical Co., Ltd. has been approved to treat NCPcausing critical or several systemic inflammatory response syndrome and multiple organ failure. Though Xuebijing is made of Chinese herbal medicine extract, the main component is safflower yellow A. Some users may occasionally have red itch on the skin, which can still disappear soon after stopping taking the medicine.

$8 \mathrm{mg} / \mathrm{kg}$ dosage of tocilizumab was taken in intravenous infusions consecutively twice and the interval between administrations was $12 \mathrm{~h}$; this is a kind of IL-6 inhibitor and could significantly improve acute respiratory distress syndrome (ARDS), which may result from a hyperinflammatory syndrome (HIS), as assessed by Brescia COVID Respiratory Severity Score (BCRSS 0 to 8, with higher scores indicating higher severity) at 24-72 $\mathrm{h}$ and 10 days after tocilizumab administration $[34,44]$.

\section{The Value of Lopinavir / Ritonavir in Treatment of COVID-19}

The commonly used agents for antiviral treatment of COVID19 all over the world included chloroquine, hydroxychloroquine, lopinavir/ritonavir, favipiravir, remdesivir, nitazoxanide, and ivermectin; they have proved their efficiency in inhibiting SARS-CoV-2 in vivo or in vitro, and some of them are licensed for the treatment of some other human infections [45]. Chloroquine (CQ) and hydroxychloroquine (HCQ) are aminoquinolines, which have been used to treat malaria and autoimmune diseases for over 50 years; these drugs interfere with the glycosylation of ACE2 receptor which prevents SARS-CoV-2 receptor binding and subsequent infection. Recent in vitro studies reported CQ and HCQ effective against SARS-CoV-2 at a multiplicity of infection (MOI) of 0.01 with a $50 \%$ effective concentration (EC50) of $2.71 \mu \mathrm{M}$ and $4.51 \mu \mathrm{M}$ in Vero E6 cells, respectively. Favipiravir can selectively and potently inhibit the RNAdependent RNA polymerase (RdRp) of RNA viruses; it has been shown to be effective in the treatment of influenza and in some extent Ebola virus disease; in an in vitro study, SARSCoV-2 was inhibited by favipiravir in Vero E6 cells with an EC50 of $61.88 \mu \mathrm{Mol}$ [46]. Remdesivir is a novel antiviral drug developed originally for the treatment of Ebola virus disease and Marburg virus infections; in vitro testing has also shown that remdesivir has activity against SARS-CoV-2 with an EC50 value of $1.76 \mu \mathrm{M}$ in Vero E6 cells which means that we can achieve its working concentration from nonhuman primate models possibly [47].

Lopinavir is a kind of protease inhibitor of human immunodeficiency virus 1 (HIV-1), and ritonavir was commonly used to increase the half-life of lopinavir by inhibiting cytochrome P450 in combination. The feasibility of the combination of lopinavir/ritonavir was mentioned in the latest
Guideline of Diagnosis and Treatment of COVID-19 because of the success in treating MERS. The results from in vitro experiments showed that lopinavir/ritonavir could limit the replication of coronavirus to a certain extent.

During the SARS epidemic period in 2003, scholars in Hong Kong found that 44 SARS patients treated with the combination of lopinavir/ritonavir with corticosteroid and ribavirin in the initial medical state, and 31 SARS patients treated with lopinavir/ritonavir in the clinical deteriorating period, on one hand, had suffered less from ARDS or lower mortality compared with 111 SARS patients of whom lopinavir/ ritonavir therapy was absent (Table 1); on the other hand, the virus load of SARS-CoV significantly cuts down in nasopharyngeal, serum, excrement, and urine samples relative to the group treated with ribavirin alone (Table 2) [48]. Lopinavir/ritonavir or interferon- $\beta 1 \mathrm{~b}$ could also significantly inhibit MERS-CoV in common marmosets [49]. The Kingdom of Saudi Arabia launched a randomized controlled trial (NCT02845843) on whether lopinavir/ritonavir combined with interferon- $\beta$ improves the clinical outcome of patients with MERS-CoV and the research is still in progress yet.

Health workers in Korea found an index COVID-19 pneumonia patient who had caused tertiary transmission locally and proved that the treatment of lopinavir/ritonavir could prominently reduce $\beta$-coronavirus, which was monitored by quantitative RT-PCR. The COVID-19 patient started to take two tablets (lopinavir $200 \mathrm{mg}$ /ritonavir $50 \mathrm{mg}$ ) orally from the 10 th day after the onset of the disease; the $\beta$-coronavirus load level came to the lower level, and no detectable or little virus titers were tested since the next day (Fig. 1). The authors speculated the outcome of a reduced load of SARS-CoV-2, thanks to the heritable healing function instead of lopinavir/ ritonavir, or both [36]. Nevertheless, colleagues have observed that lopinavir/ritonavir might aggravate the condition of some patients, or made other patients have a fever, who did not previously, after taking the medicine. They have also

Table 1 Summary of literature reported cases in the medical management of SARS in immune-competent host [48]

\begin{tabular}{llc}
\hline Therapies & $\begin{array}{l}\text { Number } \\
\text { of cases }\end{array}$ & Mortality (\%) \\
\hline $\begin{array}{l}\text { Conservative supportive } \\
\text { treatment }\end{array}$ & 13 & $2(15.4 \%)$ \\
$\begin{array}{l}\text { Initial medical management } \\
\text { Ribavirin and corticosteroid }\end{array}$ & 611 & $47(7.7 \%)$ \\
$\quad \begin{array}{l}\text { Lopinavir/ritonavir, ribavirin, } \\
\text { and corticosteroid }\end{array}$ & 44 & $1(2.3 \%)$ \\
$\quad$ Corticosteroid & 14 & $2(14.3 \%)$ \\
$\begin{array}{l}\text { Rescue medical treatment } \\
\text { Ribavirin and corticosteroid }\end{array}$ & 12 & $1(8.3 \%)$ \\
Lopinavir/ritonavir & 31 & $4(12.9 \%)$ \\
\hline
\end{tabular}


Table 2 Correlation of treatment intervention and quantitative RT-PCR of clinical specimens between day 10 and 15 in 152 patients with SARS [48]

Treatment intervention
Mean (SD) virus load $\left(\log _{10}\right.$ copies $\left./ \mathrm{ml}\right)$

Nasopharyngeal specimens
$1.3(2.6)$
2.8(3.1)
$<0.01$

\section{Serum}

$0.4(0.9)$

$1.4(1.5)$

0.04
4.3(3.3)

$6.9(2.6)$

$<0.01$
Urine

$0.5(1.4)$

$1.7(2.3)$

$<0.01$ noticed that lopinavir/ritonavir have toxic side effects on the liver and heart. What's more, the clinical trials of the novel coronavirus pneumonia on NCP patients are completed; we believe that we will get access to the preliminary results of the evaluation soon [50].

\section{Rehabilitation Standard}

The body temperature has recovered for more than 3 days, the respiratory symptoms and pulmonary imaging performance improved significantly [26], the respiratory pathogenic nucleic acid test was negative for two consecutive times (the sampling interval was not less than 1 day) [5], and the duration of disease was $\geq 14$ days, wherein patients could be released from hospital isolation and discharged or transferred to the corresponding department according to the condition for treatment of other diseases [19]. What's more, the criterion of CT imaging of the lung should be satisfied as follows: (1) or (2) + (3). (1) The area of the lesion is reduced $\geq 50 \%$, without new exudative lesion; (2) the density of focus is reduced $\geq 50 \%$, without new exudative focus; and (3) a small amount of pleural effusion is absorbed or without elevation [51-53].
It is highly recommended to continue home isolation for 2 weeks after rehabilitation and discharge.

\section{Conclusion}

At last, every health worker should strengthen the awareness of protection and struggle to do the best in prevention and control in NCP in an all-round way in the current rough, to protect the interests of patients, their family members, and the pioneers in the frontline themselves to the maximum extent. It is a long story for us to witness the great breakthrough in specific antiviral drugs or vaccines for $2019-\mathrm{nCoV}$, and we decide the prescription mainly based on the success on preventing and controlling SARS, MERS, or some other new influenza virus. Anyway, the active symptomatic support was the key to fighting COVID-19. We hold the opinion that lopinavir/ritonavir would be the useful material for alleviating COVID-19, and the thorough efficacy of the drug deserves further investigation. We hope to serve as a pioneer for further discussions about this emergency prevention event, and direct the medical workers in another area to diagnose and treat the NCP patients during the tough emergency time, just for
Fig. 1 SARS-CoV-2 starts to decrease from the next day of taking lopinavir/ritonavir. Quantitative analysis of beta $\mathrm{CoV}$ (a) and SARS-CoV-2 (b) in sputum samples collected from the NCP patient everyday by RTPCR. The results showed a temporary decline of virus titers with time and no detectable RdRP titer at illness days 12 and 13. RTPCR reverse transcriptionpolymerase chain reaction, RdRP RNA-dependent RNA polymerase, $C t$ cycle threshold, $\Delta C t^{-} \mathrm{Ct}$ (target gene) $-{ }^{-} \mathrm{Ct}$ (internal control) [36]
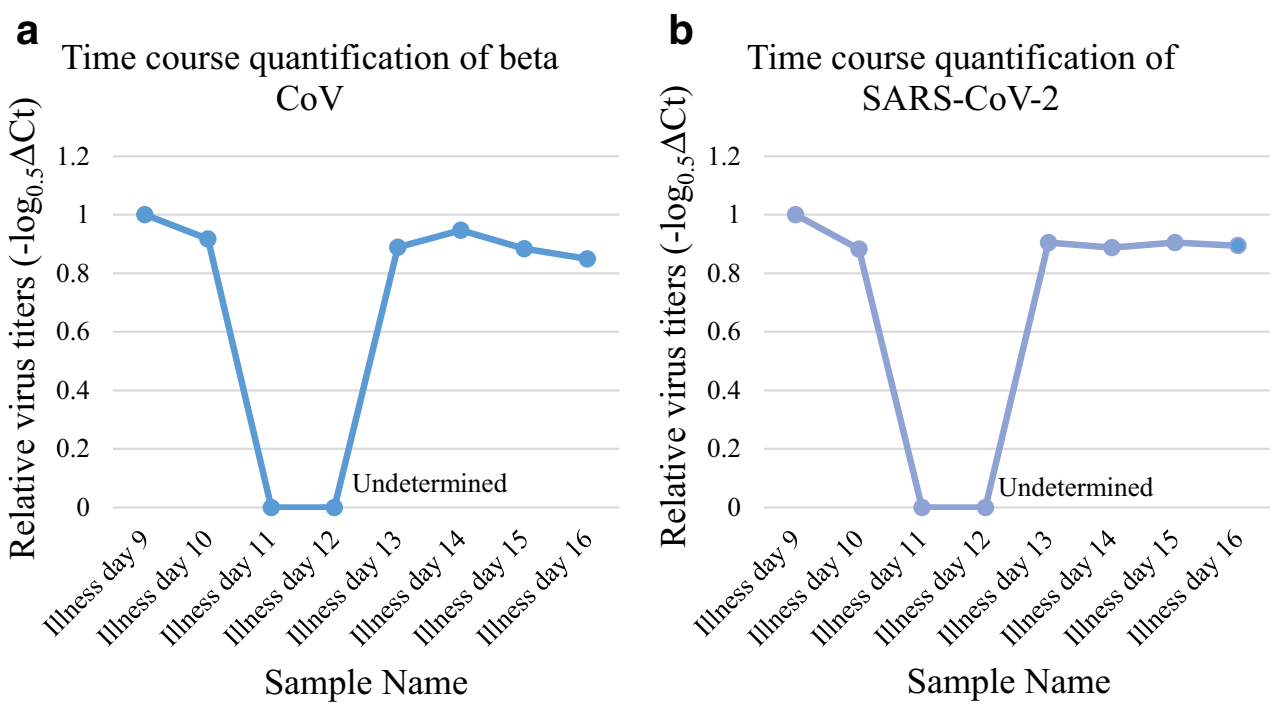
improving the clinical practice around disaster area as soon as possible.

Authors' Contribution We confirmed that every author has participated in the accomplishment of this review. And every author has witnessed the final version and approved its publication. Dai Y and Tang D made substantial contributions to the conception or design of the work. Peng $\mathrm{W}$ was in charge of collecting materials and putting forward innovation points. Song Y drafted the work and revised it critically for important intellectual content and agreed to be accountable for all aspects of the work in ensuring that questions related to the accuracy or integrity of any part of the work are appropriately investigated and resolve.

\section{Compliance with Ethical Standards}

Conflict of Interest The authors declare that they have no conflict of interest.

Ethical Approval None.

Informed Consent None.

\section{References}

1. Zhu N, Zhang D, Wang W, Li X, Yang B, Song J, et al. A novel coronavirus from patients with pneumonia in China, 2019. N Engl J Med. 2020;382:727-33.

2. Chen J. Pathogenicity and transmissibility of 2019-nCoV-A quick overview and comparison with other emerging viruses. Microbes Infect. 2020;22:69-71.

3. Huang C, Wang Y, Li X, Ren L, Zhao J, Hu Y, et al. Clinical features of patients infected with 2019 novel coronavirus in Wuhan, China. Lancet. 2020;395:497-506.

4. Chan JF, Kok KH, Zhu Z, Chu H, To KK, Yuan S, et al. Genomic characterization of the 2019 novel human-pathogenic coronavirus isolated from a patient with atypical pneumonia after visiting Wuhan. Emerg Microbes Infect. 2020;9(1):221-36.

5. Chu DKW, Pan Y, Cheng SMS, Hui KPY, Krishnan P, Liu Y, et al. Molecular diagnosis of a novel coronavirus (2019-nCoV) causing an outbreak of pneumonia. Clin Chem. 2020;66:549-55.

6. World Health Organization. WHO Director-General's remarks at the media briefing on 2019-nCoV on 11 February 2020. https:// www.who.int/dg/speeches/detail/who-director-general-s-remarksat-the-media-briefing-on-2019-ncov-on-11-february-2020. 2020.

7. World Health Organization. Statement on the second meeting of the International Health Regulations (2005) Emergency Committee regarding the outbreak of novel coronavirus (2019-nCoV). https:// www.who.int/dg/speeches/detail/who-director-general-s-remarksat-the-media-briefing-on-2019-ncov-on-11-february-2020. 2020.

8. Zhou P, Yang XL, Wang XG, Hu B, Zhang L, Zhang W, et al. A pneumonia outbreak associated with a new coronavirus of probable bat origin. Nature. 2020;579:270-3.

9. Wu A, Peng Y, Huang B, Ding X, Wang X, Niu P, et al. Genome composition and divergence of the novel coronavirus (2019-nCoV) originating in China. Cell Host Microbe. 2020;27:325-8.

10. Baruah $\mathrm{V}$, Bose $\mathrm{S}$. Immunoinformatics-aided identification of $\mathrm{T}$ cell and B cell epitopes in the surface glycoprotein of 2019nCoV. J Med Virol. 2020;92:495-500.

11. Doyle D, Credille B, Lehenbauer TW, Berghaus R, Aly SS, Champagne J, et al. Agreement among 4 sampling methods to identify respiratory pathogens in dairy calves with acute bovine respiratory disease. J Vet Intern Med. 2017;31(3):954-9.
12. The L. Emerging understandings of 2019-nCoV. Lancet. 2020;395(10221):311.

13. Guarner J. Three emerging coronaviruses in two decades. Am J Clin Pathol. 2020;153:420-1.

14. Tuite AR, Fisman DN. Reporting, epidemic growth, and reproduction numbers for the 2019 novel coronavirus (2019-nCoV) epidemic. Ann Intern Med. 2020.

15. Gralinski LE, Menachery VD. Return of the coronavirus: 2019nCoV. Viruses. 2020;12(2).

16. Hui DS, Azhar EI, Madani TA, et al. The continuing 2019-nCoV epidemic threat of novel coronaviruses to global health - The latest 2019 novel coronavirus outbreak in Wuhan, China. Int J Infect Dis. 2020;91:264-6.

17. Song F, Shi N, Shan F, et al. Emerging coronavirus 2019-nCoV pneumonia. Radiology. 2020;200274.

18. Xu YH, Dong JH, An WM, Lv XY, Yin XP, Zhang JZ, et al. Clinical and computed tomographic imaging features of novel coronavirus pneumonia caused by SARS-CoV-2. J Infect. 2020;80: 394-400.

19. Jin YH, Cai L, Cheng ZS, Cheng H, Deng T, Fan YP, et al. A rapid advice guideline for the diagnosis and treatment of 2019 novel coronavirus (2019-nCoV) infected pneumonia (standard version). Mil Med Res. 2020;7(1):4.

20. Li Z, Yi Y, Luo X, Xiong N, Liu Y, Li S, et al. Development and clinical application of a rapid IgM-IgG combined antibody test for SARS-CoV-2 infection diagnosis. J Med Virol. 2020.

21. Zhao S, Lin Q, Ran J, Musa SS, Yang G, Wang W, et al. Preliminary estimation of the basic reproduction number of novel coronavirus (2019-nCoV) in China, from 2019 to 2020: a datadriven analysis in the early phase of the outbreak. Int J Infect Dis. 2020.

22. Chung M, Bernheim A, Mei X, Zhang N, Huang M, Zeng X, et al. CT imaging features of 2019 novel coronavirus (2019-nCoV). Radiology. 2020:200230.

23. LI T, Cao W, Wen L, et al. Diagnosis and clinical management of 2019 novel coronavirus (2019-nCoV) infection: an operational recommendation of Peking Union Medical College Hospital. Med J Peking Union Med Coll Hosp. 2020;11.

24. Biscayart C, Angeleri P, Lloveras S, Chaves T, Schlagenhauf P, Rodriguez-Morales AJ. The next big threat to global health? 2019 novel coronavirus (2019-nCoV): what advice can we give to travellers? - interim recommendations January 2020, from the LatinAmerican society for Travel Medicine (SLAMVI). Travel Med Infect Dis. 2020;101567.

25. Rubin EJ, Baden LR, Morrissey S, Campion EW. Medical journals and the 2019-nCoV outbreak. N Engl J Med. 2020.

26. Pan Y, Guan H. Imaging changes in patients with 2019-nCov. Eur Radiol. 2020;30:3612-3.

27. Chen L, Liu W, Zhang Q, Xu K, Ye G, Wu W, et al. RNA based mNGS approach identifies a novel human coronavirus from two individual pneumonia cases in 2019 Wuhan outbreak. Emerg Microbes Infect. 2020;9(1):313-9.

28. Wang D, Hu B, Hu C, Zhu F, Liu X, Zhang J, et al. Clinical characteristics of 138 hospitalized patients with 2019 novel coronavirus-infected pneumonia in Wuhan, China. Jama. 2020.

29. MacLaren G, Fisher D, Brodie D. Preparing for the Most critically ill patients with COVID-19: the potential role of extracorporeal membrane oxygenation. JAMA. 2020;323:1245.

30. Peng W, Liu S, Meng J, Huang J, Huang J, Tang D, et al. Profiling the TRB and IGH repertoire of patients with H5N6 avian influenza virus infection by high-throughput sequencing. Sci Rep. 2019;9(1): 7429.

31. Wan Y, Shang J, Graham R, Baric RS, Li F. Receptor recognition by novel coronavirus from Wuhan: an analysis based on decadelong structural studies of SARS. J Virol. 2020;94. 
32. Nguyen TM, Zhang Y, Pandolfi PP. Virus against virus: a potential treatment for 2019-nCov (SARS-CoV-2) and other RNA viruses. Cell Res. 2020;30:189-90.

33. Zumla A, Hui DS, Azhar EI, Memish ZA, Maeurer M. Reducing mortality from 2019-nCoV: host-directed therapies should be an option. Lancet. 2020;395:e35-6.

34. Yousefi B, Valizadeh S, Ghaffari H, Vahedi A, Karbalaei M, Eslami M. A global treatments for coronaviruses including COVID-19. J Cell Physiol. 2020.

35. Richardson P, Griffin I, Tucker C, Smith D, Oechsle O, Phelan A, et al. Baricitinib as potential treatment for $2019-\mathrm{nCoV}$ acute respiratory disease. Lancet. 2020;395:e30-1.

36. Lim J, Jeon S, Shin HY, Kim MJ, Seong YM, Lee WJ, et al. Case of the index patient who caused tertiary transmission of COVID-19 infection in Korea: the application of lopinavir/ritonavir for the treatment of COVID-19 infected pneumonia monitored by quantitative RT-PCR. J Korean Med Sci. 2020;35(6):e79.

37. Yen HL. Current and novel antiviral strategies for influenza infection. Curr Opin Virol. 2016;18:126-34.

38. Wang M, Cao R, Zhang L, Yang X, Liu J, Xu M, et al. Remdesivir and chloroquine effectively inhibit the recently emerged novel coronavirus (2019-nCoV) in vitro. Cell Res. 2020.

39. Li X, Liu M, Zhao Q, Liu R, Zhang H, Dong M, et al. Preliminary recommendations for lung surgery during SARS-CoV-2 novel coronavirus pneumonia epidemic period. Chin J Lung Cancer. 2020;23(3):133-5.

40. Via M, Scurlock C, Raikhelkar J, Di Luozzo G, Mechanick JI. Chromium infusion reverses extreme insulin resistance in a cardiothoracic ICU patient. Nutr Clin Pract. 2008;23(3):325-8.

41. Kim MH, Kim HJ, Chang J. Superior immune responses induced by intranasal immunization with recombinant adenovirus-based vaccine expressing full-length spike protein of Middle East respiratory syndrome coronavirus. PLoS One. 2019;14(7):e0220196.

42. Hou F, Huang JM, Zhang R, Li L, Li G. An experimental study on the regulation of bone marrow-derived mesenchymal stem cells through indoleamine 2,3-dioxygenase signaling pathway by thymosin alpha1 for improving the immunosuppression mediated by T cell. Zhonghua er ke za zhi $=$ Chin J Pediatr. 2011;49(3):181-5.

43. Song Y, Yao C, Yao Y, Han H, Zhao X, Yu K, et al. XueBiJing injection versus placebo for critically ill patients with severe community-acquired pneumonia: a randomized controlled trial. Crit Care Med. 2019;47(9):e735-e43.

44. Toniati P, Piva S, Cattalini M, Garrafa E, Regola F, Castelli F, et al. Tocilizumab for the treatment of severe COVID-19 pneumonia with hyperinflammatory syndrome and acute respiratory failure: a single center study of 100 patients in Brescia, Italy. Autoimmun Rev. 2020;19(7):102568.

45. Şimşek Yavuz S, Ünal S. Antiviral treatment of COVID-19. Turk J Med Sci. 2020;50(SI-1):611-9.

46. Gautret P, Lagier JC, Parola P, Hoang VT, Meddeb L, Mailhe M, et al. Hydroxychloroquine and azithromycin as a treatment of COVID-19: results of an open-label non-randomized clinical trial. Int J Antimicrob Agents. 2020;105949.

47. Wang M, Cao R, Zhang L, Yang X, Liu J, Xu M, et al. Remdesivir and chloroquine effectively inhibit the recently emerged novel coronavirus (2019-nCoV) in vitro. Cell Res. 2020;30(3):269-71.

48. Cheng VC, Tang BS, Wu AK, Chu CM, Yuen KY. Medical treatment of viral pneumonia including SARS in immunocompetent adult. J Infect. 2004;49(4):262-73.

49. Chan JF, Yao Y, Yeung ML, Deng W, Bao L, Jia L, et al. Treatment with lopinavir/ritonavir or interferon-betalb improves outcome of MERS-CoV infection in a nonhuman primate model of common marmoset. J Infect Dis. 2015;212(12):1904-13.

50. Du B, Qiu HB, Zhan X, Wang YS, Kang HYJ, Li XY, et al. Pharmacotherapeutics for the new coronavirus pneumonia. Zhonghua Jie He He Hu Xi Za Zhi. 2020;43(0):E012.

51. Zhao S, Musa SS, Lin Q, Ran J, Yang G, Wang W, et al. Estimating the unreported number of novel coronavirus (2019-nCoV) cases in China in the first half of January 2020: a data-driven modelling analysis of the early outbreak. J Clin Med. 2020,9(2).

52. Lei J, Li J, Li X, Qi X. CT Imaging of the 2019 Novel coronavirus (2019-nCoV) pneumonia. Radiology. 2020:200236.

53. Shi H, Han X, Zheng C. Evolution of CT manifestations in a patient recovered from 2019 novel coronavirus (2019-nCoV) pneumonia in Wuhan, China. Radiology. 2020:200269.

Publisher's Note Springer Nature remains neutral with regard to jurisdictional claims in published maps and institutional affiliations. 